\title{
COMPUTATIONAL MODEL FOR CONDITION ANALYSIS AND EQUIPMENT MONITORING
}

\author{
Álvaro Souza de Araújo ${ }^{1}$, Oberdan Pinheiro Rocha ${ }^{a}$, Alex Álisson Bandeira Santos ${ }^{a}$ \\ a SENAI CIMATEC, Brazil
}

\begin{abstract}
Predictive maintenance uses several methods to monitor the conditions of electric motors applied in industrial plants. Among these methods, vibration analysis stands out as a widely used method due to the possibility of identifying a wide possibility of failures. This work presents the development of a computational model equipped with a classifier algorithm to receive vibration readings from electric motors and determine if the machine presents a failure behavior and, if so, which failure. For the algorithm to be able to detect the type of failure, a dataset will be developed with readings from several engines in various failure conditions for training the model.
\end{abstract}

Keywords: vibration analysis, condition-based monitoring, classifying agent

\section{MODELO COMPUTACIONAL PARA ANÁLISE DE CONDIÇÕES E MONITORAMENTO DE EQUIPAMENTOS}

Resumo: A manutenção preditiva utiliza de diversos métodos para acompanhamento das condições dos motores elétricos aplicados em plantas industriais. Dentre estes métodos, destaca-se a análise de vibração como método amplamente utilizado devido à possibilidade de identificação de uma vasta possibilidade de falhas. Este trabalho apresenta o desenvolvimento de um modelo computacional dotado de um algoritmo classificador para receber leituras de vibração de motores elétricos e determinar se a máquina apresenta um comportamento de falha e, em caso positivo, qual falha. Para que o algoritmo seja capaz de detectar o tipo de falha, será desenvolvido um dataset com leituras de diversos motores em variadas condições de falha para treinamento do modelo.

Palavras-chave: análise de vibração, monitoramento baseado em condições, agente classificador 


\section{INTRODUCTION}

Maintenance is a critical and constantly evolving point in the industries. Even with several technological advances, it is still a challenge to predict failures before they occur. According to Senanayaka et al. [1], preventive maintenance has been used in the industry to perform actions in equipments in a predefined schedule. However, the main drawback of this approach is the need for stopping the equipments to start the maintenance process, yielding higher costs, especially due to the stopped machines, since the availability of the machines are a main objective in the industry, according to Prudhom et al. [2].

Condition based monitoring is necessary, especially in the industrial environment, where the failure of a certain equipment that results in the need for corrective maintenance, may cause partial or total stoppage of the production plant, which causes inconvenience and losses for the company. The nondestructive vibration analysis of the rotating systems is one of the most used techniques that offer a real and best solution to bearings fault diagnosis, as reported by Attoui et al. [3].

To mitigate the possibility of failure, vibration analysis is performed in electric motors. This method is an important tool for diagnosing operational conditions. Many engine problems reflect directly on their vibration due to several factors: misalignment, cavitation, clearances, among others. Each component of an engine has a signature at a different frequency, so, based on the analysis of the behavior of the equipment's vibration profile, it is possible to detect the type of failure present on the machine.

Companies rely on vibration analysis equipment to perform this type of detection. However, this equipment requires extensive knowledge in its operation, besides the high acquisition cost and the operation limitation, since the operator performs the analysis on one equipment at a time, requiring a subsequent analysis of the results by a specialist. This process requires time, high costs and is subject to failure during the analysis of the results.

Thus, with the use of an algorithm equipped with a classifying agent and a dataset with several analyzes to allow the training of this system, the process of evaluation of the conditions of the engines will become faster, more efficient, besides allowing reductions in the operational costs. Artificial intelligent techniques, such as artificial neural networks (ANNs) and fuzzy logic, etc., have been successfully applied to automated detection and diagnosis of machine conditions, according to Lei et al. [4].

Current studies show classifying algorithms specialized in a specific failure, which does not allow the implementation of these in an industrial environment to obtain indications of several failures, since the application of an electric motor can induce defects in different components of this equipment.

Despite being the most common type of failures, at about $40 \%$, as per the study from Çaliş et al. [5], there are other types of failures, regarding axes misalignment, imbalance, or even due to improper mounting, in case of high-power motors. Those faults can also be detected using vibration monitoring.

To fill this gap, this research project aims to develop a classifier algorithm that, based on a dataset containing readings of different equipment, will determine the current condition of an electric motor. To make this research feasible, the dataset must be obtained in the laboratory, with the help of industrial vibration analysis equipment. 
Different engine classes, based on their powers, will be included in the collection, to allow the model to be applied to a wide range of equipment. In the laboratory, different equipment failures will be induced so that the model is able to detect several anomalies.

A variety of classification methods will also be evaluated, to obtain what will bring greater precision and accuracy in the detection of the failure, in the shortest execution time and with the smallest error. After training the network using the model that best fits the problem resolution, the technical feasibility of the proposed model will be analyzed based on laboratory tests.

With the aid of UML diagrams, it is possible to visualize the functioning of the model, as well as interactions with users. This type of modeling is widely used for systems design and encompasses a set of diagram models applicable to different scenarios and modeling needs.

This paper presents a model proposal for the algorithm to perform the analysis of a motor vibration signal to determine the presence of a possible fault, and, if positive, calculate the severity level, as well as report the fault type, according to a dataset with multiple fault conditions, specifically created to feed this model.

\section{METHODOLOGY}

After statistical analysis, Prudhom et al. [2] concluded in his research that most electric motor failures are related to bearings, often due to the use of incorrectly installed frequency inverters. These defects can be easily detected through vibration analysis.

Most of the defects evaluated during operation can be related to the use of Variable Frequency Drives (VFD), since in a PWM switched three phase power supply, perfect balance between phases is not achieved instantaneously; this causes a potential between the inverter output and earth which will force currents through stray impedances in the motor cables and motor windings, according to Prudhom et al. [2].

Rotor failures are also common in an industrial environment. These conditions do not lead to an immediate breakdown of the equipment, but it generates disturbances that deteriorate its condition, when in operation, as stated by Abdelkrim [6]. However, there are other faults that occur and that can also be detected by this method of predictive maintenance, such as shaft misalignment or imbalance.

To evaluate the signal in the frequency spectrum, it is used the Fourier Transform: a mathematical algorithm that converts the input signal into a sum of multiple sinusoidal waves with different frequencies. With this approach, it is possible to evaluate the magnitude of the frequencies that compose this given signal. Since every fault condition corresponds to a unique combination of frequencies, this analysis allows to determine which condition of failure a given vibration signal corresponds to.

With this research it is possible to obtain a classifier algorithm to identify and classify the behavior of an electric motor through the analysis of the vibration spectrum. This classifier can determine which fault is closest to the one obtained by reading, if it has one, as well as the degree of severity, based on the ISO 10816 standard that 
classifies vibration levels for engine categories. This allows an intervention before the equipment is unable to operate in its proper conditions.

To detect the vibration patterns, the model must be trained with data obtained from real running equipments. Therefore, in this research will also be conducted a vibration data collection with professional and certified equipment to create a dataset, containing readings from different sized equipments, under different fault conditions. Furthermore, it will be evaluated the technical feasibility of the model, as well as the dataset generated through tests in laboratory.

\subsection{ISO 10816}

This regulation, exemplified in Figure 1, divides electric motors into four categories, based on power and installation. For a small motor, rated up to $20 \mathrm{HP}$, withstand vibrations up to $0.71 \mathrm{~mm} / \mathrm{s}$ in normal operation. Up to $1.8 \mathrm{~mm} / \mathrm{s}$ is considered satisfactory, however it is necessary to observe the behavior of the frequency spectrum so that a fault is diagnosed to prevent the equipment from operating in unacceptable conditions.

In addition to the power category, motors are also classified based on the foundation structure where they are installed, for high power equipment. Observation of the installation of the equipment is important, as a rigid foundation does not allow the dissipation in mechanical energy from engine vibration as in a flexible foundation. Each type of installation is indicated for different operating frequencies.

Figure 1. ISO 10816 vibration severity levels

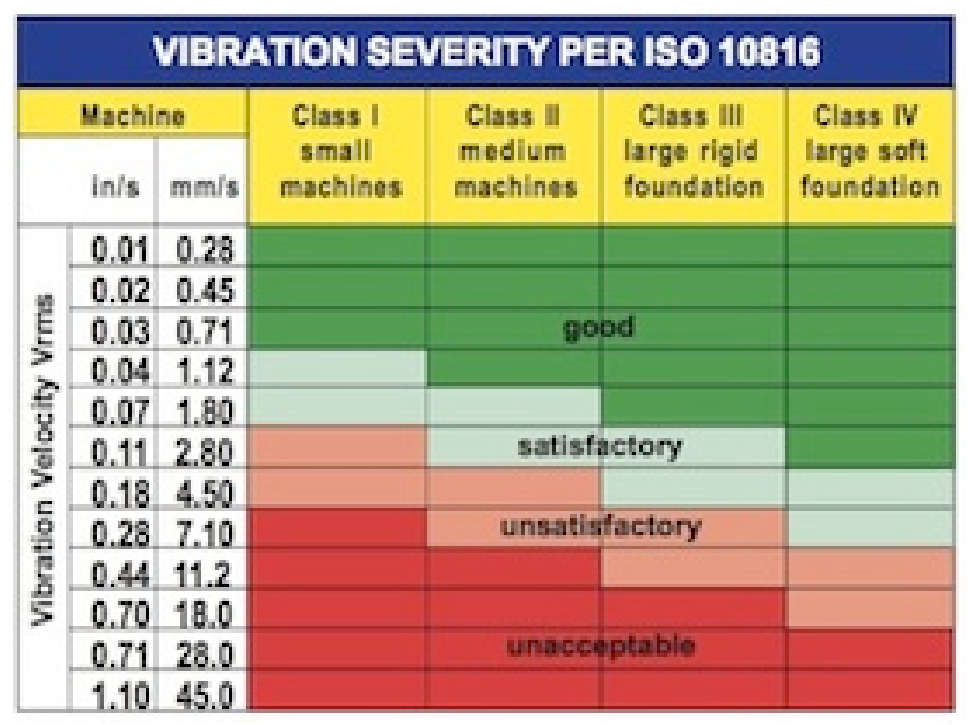

Besides the vibration levels, the analysis of the frequency spectrum allows a detailed analysis of the behavior of a rotating equipment, in comparison with the signal in the time domain. Each fault condition in the motor contains a different vibration signature, where different defects will result in variation of magnitude as well as peaks of frequency and the presence or absence of relevant harmonics. 


\subsection{Classifier model}

To understand the requirements of the model, it will be used modeling with the UML standard (Unified Modeling Language), which is an internationally recognized technique, due to its integration with object-oriented programming concepts. From the development of the diagrams that best describe the problem, the process of making documents becomes easier and more efficient.

Within this set of diagrams, there are those with a focus on structure, behaviors, and interactions. The former, as a class and component diagram, allow the visualization of the structure of the static components of the model, including operations and attributes. The second type, like the use-case diagram, details the behavior of parts of the system and the exchange of information between them. Finally, interaction or sequence functions work in a similar way to behavioral ones, focusing only on the interaction between the parts of the system.

Figure 2. Activities diagram of the proposed model

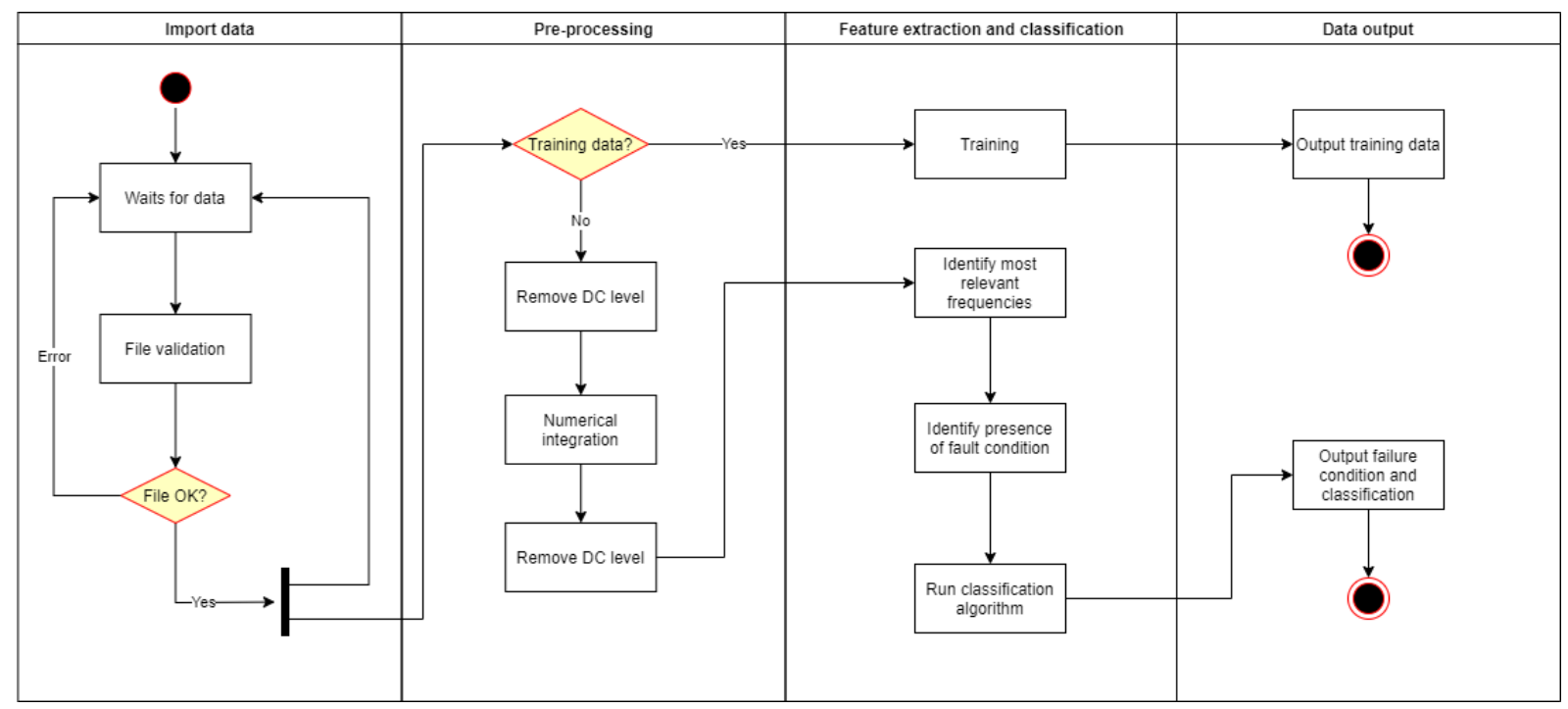

In addition to being able to detect the presence of faults, the proposed model also analyzes the frequency spectrum of the signal obtained to classify the type of fault present in the equipment. Each type of defect represents a unique behavior in frequency that, with a trained network with a dataset composed of a variety of behaviors, it is possible to use the classifier algorithm to determine which of the patterns best represents the current state of the machine.

The system receives the data from the equipment to be analyzed by means of an industrial vibration analysis equipment that allows exporting the data in csv format. The data contained in this file correspond to the readings of the frequency spectrum and their respective magnitudes under acceleration.

When importing the data, the model performs a pre-processing step, where the data is converted to speed values, so that it can be compared with the definitions of the standard. This is done via numerical integration methods. However, to reduce the 
error generated by an integration, the continuous level present on the signal must be removed before and after the process, as reported by Zhu et al. [7]. Furthermore, when calculating the Fast Fourier Transform (FFT), any continuous level will result in a peak in amplitude at the frequency zero, compromising the algorithm's analysis.

To analyze the frequency spectrum, the model will calculate the Fourier Transform for the received signal, to determine the magnitude of each frequency, within the resolution of the devices used to measure the vibration of the motor. This method consists of a mathematical algorithm to decompose a given signal into a sum of multiple sinusoidal components, with different frequencies and amplitudes.

Then, the most relevant frequencies are highlighted so that the algorithm can determine and which of the operating ranges this behavior fits, so that the classifier algorithm that determines which failure the equipment has, is executed.

\section{RESULTS AND DISCUSSION}

Before the execution of the classifier algorithm, previous steps are necessary for the integration of the received acceleration signal and the subsequent filtering of the resulting signal to extract the average level of the signal, especially after the integration process that results in a constant value added to the operation. Then, the system extracts the most relevant frequencies, as these will determine the presence of some fault condition, based on the determination of ISO 10816.

From the confirmation of an anomalous behavior in the reading, the system now proceeds with the detection of the type of failure, from a classifier algorithm trained with a dataset generated with readings of several equipment with failures. The result is returned to the user, informing whether the analyzed equipment has a fault condition and which, if so.

\section{CONCLUSION}

From the studies of modeling techniques and with the understanding of the model's needs, it was evaluated which models are necessary to describe the model in question. For this, the use case and sequence diagram were chosen, as the system performs the classification process in stages. Thus, the interaction with the user occurs during data entry and the return of the result of the process, indicating the presence of the failure, as well as the degree of severity, if any.

UML modeling has a variety of diagram models, each with its own purpose that, when used together, allows the system to be viewed from different perspectives, which makes the development and documentation process more efficient. In addition, it allows knowledge of all the components and functionalities of the modeled system from the conception of the idea. 


\section{REFERENCES}

1 SENANAYAKA, Jagath Sri Lal et al. Early detection and classification of bearing faults using support vector machine algorithm. In: 2017 IEEE Workshop on Electrical Machines Design, Control and Diagnosis (WEMDCD). IEEE, 2017. p. 250-255.

${ }^{2}$ PRUDHOM, Aurelien et al. Time-frequency vibration analysis for the detection of motor damages caused by bearing currents. Mechanical Systems and Signal Processing, v. 84, p. 747-762, 2017.

3 ATTOUI, Issam et al. A new time-frequency method for identification and classification of ball bearing faults. Journal of Sound and Vibration, v. 397, p. 241265, 2017.

${ }^{4} \mathrm{LEI}$, Yaguo; HE, Zhengjia; ZI, Yanyang. A new approach to intelligent fault diagnosis of rotating machinery. Expert Systems with applications, v. 35, n. 4, p. 1593-1600, 2008.

${ }^{5}$ ÇALIŞ, Hakan; CAKIR, ABDÜLKADIR; DANDIL, Emre. Artificial immunity-based induction motor bearing fault diagnosis. Turkish Journal of Electrical Engineering \& Computer Sciences, v. 21, n. 1, 2013.

${ }^{6} \mathrm{ABDELKRIM}$, Choug et al. Detection and classification of bearing faults in industrial geared motors using temporal features and adaptive neuro-fuzzy inference system. Heliyon, v. 5, n. 8, p. e02046, 2019.

${ }^{7}$ ZHU, Yong et al. An Accurate Integral Method for Vibration Signal Based on Feature Information Extraction. Shock \& Vibration, v. 2015, 2015. 